\title{
The Impact of Stem Cells on Parenteral Phase of Experimental Trichinosis during Vaccination Trial
}

\author{
Samia E. Etewa1', Samira M. Mohammad', Amira A. Saleh', \\ Eman H. Abdelbary ${ }^{2}$, Eman M. Mostafa ${ }^{1}$ \\ ${ }^{1}$ Department of Medical Parasitology, Faculty of Medicine, Zagazig University 44519, \\ Egypt. \\ ${ }^{2}$ Department of Medical Pathology, Faculty of Medicine, Zagazig University 44519, \\ Egypt.
}

Corresponding Author

Eman M. Mostafa

Mobile:

$+201152664614$

E mail:

emanmostafa81@

gmail.com

Key words:

Trichinellosis, crude larval antigen, bone marrow mesenchymal stem cells, CD8+, $T N F \alpha$
Background and study aim: Trichinellosis is a severe food-borne parasitic zoonosis. The protective immunity against infection from crude larval antigens (CLA) was performed effectively which suggests that the whole larvae would be possible vaccine candidates. Bone marrow mesenchymal stem cells (BM MSCs) induce immunomodulatory impacts through affection of $\mathrm{T}$-cell proliferation and cytokine production.

Methods: Ninety healthy mice were divided into five main groups, 10 mice each, 30 mice were for attaining BM MSCs and 10 mice for CLA preparation. Group 1 \& 2 as control, Group 3: immunized with CLA then infected, Group 4: immunized with MSCs then infected. Group 5 immunized with CLA and MSCs then infected. Mice were challenged by orally infective dose with 500 Trichinella spiralis (T. spiralis) larvae.

Results: Showed that significant reduction in the number of $T$. spiralis larvae was in group 5 (received CLA + MSCs) followed by group 3 (received CLA only) then group 4 (received MSCs only) with percentage reductions of 85.4 $\%, 82 \%$ and $68.9 \%$, respectively. G2 (infected only) showed absence of CD8+ infiltration. G3 showed moderate density of CD8+ infiltration, G4 and G5 showed high density CD8+ infiltration. However, muscle sections from G2 showed high density of tumor necrosis factor $\alpha$ (TNF $\alpha$ ) infiltration; G3 showed moderate density of TNF $\alpha$ infiltration; G4 showed very low density of $\mathrm{TNF} \alpha$ infiltration and G5 showed complete absence of TNFa infiltration.

Conclusion: We concluded that immunization by CLA combined with BM MSCs as adjuvant generated T-helper type 2 (Th2)-mediated responses with increased CD8+ cell infiltration and decreased $\mathrm{TNF}-\alpha$ required for immunity against trichinellosis with a $85.4 \%$ reduction in muscle larvae compared with the control group.

\section{INTRODUCTION}

Trichinellosis, a severe food-borne zoonotic parasitic disease and a significant public health problem worldwide, is produced mainly by infection with tissue-dwelling nematode $T$. spiralis [1]; a parasitic nematode which can infect nearly every species of mammals [2]. This infection is developed by people who ingest raw or undercooked meat and meat products contaminated with encapsulated larvae [3]. In humans, the disease is usually correlated with diverse symptomatology and often uncontrolled patient mortality. Outbreaks from 55 countries have been registered, with a yearly total of 5751 cases worldwide [4]. Trichinellosis is a disease with low prevalence and is often misdiagnosed because it may be difficult to detect in low-level infections. In comparison, its clinical symptoms mimic those of several other serious illnesses, such as influenza or rheumatoid arthritis [5]. Although albendazole is the selected therapeutic agent to treat this infection, there is no absolute successful treatment [6]. 
Compared with chemotherapy, the vaccine has some benefits [7]. A single vaccination can provide lifelong protection that reduces the use of chemical antiparasitic drugs and thereby decreases the development of drug-resistant $T$. spiralis [8]. In the other side, there is a gap between the infection of Trichinella and the positive antibody IgG [9]. The worm was embedded in muscle cells when the positive antiTrichinella IgG was reported, where it was resistant to treatment with chemicals [10]. The advancement of the vaccine development has become an urgent need for human and domestic animals for control of trichinellosis [11]. The candidate vaccine against $T$. spiralis infection primarily focuses on excretory - secretory (ES) antigens with a combined or single molecular weight and other specific recombinant factors (e.g. proteases, surface proteins). In general, the inclination of protective effects of inactivated entire worms and crude retrieval of ES antigens is higher than that of a single antigen [7].

Protective immunity to $T$. spiralis infection of newborn larva-derived antigens was effectively conducted in the mouse model that suggested that vaccine candidates would be possible for the entire larvae [12]. Not only the molecules released from specialized ES organs but also the material shed from the cuticular and tegumental surfaces are the major sources of ES products [13]. It is well established that $T$. spiralis antigens are essential modulators or targets of the host immune system, either surface antigens or excreted-secreted antigens [14].

An adjuvant is a component that boosts the immune reaction to an antigen in the body. When introduced into a vaccine formulation, an immunologic adjuvant accelerates, prolongs or increases the efficiency of different immune responses to the vaccines [15]. It is important to use an efficient and secure adjuvant to improve the immune response and build defensive immunity against the parasite [12]. There are other forms of adjuvant substances, such as Freund's complete adjuvants (FCA) and Montanide ISA. FCA was deemed the gold standards of adjuvant action, but due to its very high toxicity, it is not appropriate for use in vaccine research in human or animal [16]. Due to excessive inflammation at the injection site and due to the non-metabolisable mineral oil, it can produce some immunological toxic effects, for this cause: it is only registered for use on laboratory animals [17]. Montanide ISA 51, which is a surfactant comprising both mineral oil and mannide monooleate. This adjuvant is being clinically evaluated but side-reactions, including granuloma, local irritation, tenderness and erythema, are not acceptable [18]. MSCs are non-hematopoietic stromal cells capable of differentiating themselves into mesenchymal tissues like; muscle, ligament, tendon, bone, cartilage, nerve and adipose tissue. The tissue is essential for healing after acute trauma or biological ageing [19]. In addition, MSCs have been shown to elicit immunomodulatory effects by suppressing T-cell proliferation and cytokine production which play a crucial role in inflammation [20]. Alternatively, stroma from $\mathrm{BM}$ is the most common source of tissue used to develop mesenchymal progenitors. MSCs are most commonly extracted from BM either by bone marrow harvesting utilizing a needle, or by flushing [21]. Nevertheless, MSCs were easily extracted from diverse tissues, such as Wharton's umbilical cord, muscle, fat, brain, skin and heart [22]. Stem cells have now demonstrated multiple medicinal applications for a number of diseases based on either their regenerative or immunomodulatory potential [23]. In addition, Dennis et al. [24] indicated that stem cells are unsuccessful in removing adult $T$. spiralis worms in the intestinal process when administrated orally, which is because stem cells are digested. Also, this explanation was confirmed by Shokir [25]. Furthermore, given its convenience, the oral route of MSCs administration is opposed by a biological barrier whose stem cells cannot pass, however systemic treatment, which can be done through intravenous (iv) injection, intraperitoneal injection, intraarterial injection, or intracardiac injection, may be preferred [26]. However, local stem cell therapy approaches increase complications and adverse reactions such as bleeding and tissue damage with direct tissue injection or occlusion, and embolization correlated with direct arterial administration [27]. Therefore, despite broad biodistribution and easy access, if stem cells are to be widely distributed, iv approach will be ideal [28]. The goal of the present study is to evaluate the effect of BM MSCs when used as potential adjuvant for iv immunization against trichinellosis in experimentally infected mice and to investigate the efficacy of these cells when compared to CLA by histopathology and immunohistochemistry studies. 


\section{MATERIALS \& METHODS}

Type of study: This case control experimental study was conducted in Medical Parasitology Department, Faculty of Medicine, Zagazig University, Egypt during the period from March 2019 to November 2019.

Experimental animals: Ninety healthy lab-bred male Swiss albino mice, 6-8 weeks-old, each weighing 20-25 g were used; 50 mice were included in the study groups, 30 mice were for attaining BM MSCs and 10 mice for getting encysted larvae for preparation of CLA. They were housed in well ventilated cages and fed standard pellet food with free access to water and maintained under controlled conditions of lighting (12 h light/12 $\mathrm{h}$ dark cycle) and temperature $\left(25 \pm 2^{\circ} \mathrm{C}\right)$. Animals have been anaesthetized using isoflurane, the animal inhalation anesthetic agent of choice, before doing painful procedures [29].

Parasite and infection: A strain of $T$. spiralis was kindly supplied by Medical Parasitology Department, Faculty of Medicine, Tanta University and maintained in Swiss albino mice in Medical Parasitology Department, Faculty of Medicine, Zagazig University.

Experimental Design: Mice were divided into five main groups, 10 mice each as follows: Group 1: control negative, no infection and no treatment. Group 2: control positive, infection and no treatment. Group 3: vaccinated with CLA then infected. Group 4: received MSCs then infected. Group 5: received MCSs and CLA then infected. Mice of groups 2, 3, 4 and 5 were infected orally with $500 \mathrm{~T}$. spiralis muscle larvae (ML). Mice of groups 3 and 5 were vaccinated with CLA iv (tail vein). Mice of groups 4 and 5 were given MSCs iv (tail vein).

Study assessment: This includes parasitological assessment (no. of encysted larvae in diaphragms); histopathological assessment using Periodic acid-Schiff (PAS) and Masson's Trichrome (MT) staining procedures of diaphragm muscle and immunohistochemical assessment of TNF $\alpha$ and CD8+ in muscle tissues of mice.

Preparation of CLA: After artificial digestion of contaminated mouse carcasses $(10$ mice) on day 49 post-infection (pi), muscle larvae were collected using a solution comprising $5 \%$ pepsin, $7 \% \mathrm{HCl}$ and $9 \% \mathrm{NaCl}$, in a shaker-incubator at $37 \mathrm{C}$ for 2 hours. Briefly, according to Dea-
Ayuela et al. [30], live larvae were washed by phosphate buffered saline (PBS) sedimentation (0.01 M sodium phosphate, $0.15 \mathrm{M} \mathrm{NaCl}$ ). The deposited larvae became sonicated. The crude extract was allowed to be processed at $4^{\circ} \mathrm{C}$ overnight and then centrifuged. The supernatant was obtained, and the protein content was calculated by Bradford method [31]. The samples were aliquoted and freezed at $-20^{\circ} \mathrm{C}$.

BM MSCs procedures: Briefly according to Etewa et al. [32], MSCs were obtained from BM of thirty Swiss albino male mice after flushing tibias and femurs. From our previous work, viability of cells was verified by trypan blue stain. CD105 and CD34 surface markers expression was analyzed by flow cytometry in the Clinical Pathology Laboratory, Faculty of Medicine, Zagazig University. Cell surface expression of CD105 was determined by flow cytometer analysis using $488 \mathrm{~nm}$ wavelength laser excitation. A hemocytometer was used to count and calculate the viable cells. Homing of MSCs in tissues was done using in vivo labeling of MSCs with fluorescent PKH26 stain and visualized by a fluorescent microscope. Immunization schedule and challenge protocol were summarized in Table 1.

Sampling: On $49^{\text {th }}$ day pi, all mice were sacrificed. The abdominal skin was sterilized then incised; the peritoneum was opened to dissect the diaphragm carefully and subjected to:

1. Parasitological assessment: Semiquantitative assessment by taking the average number of encysted larvae of 10 high-power field (no. of encysted larvae in diaphragms) [34].

2. Histopathological assessment: Descriptive study using i. PAS ii. MT staining procedures of diaphragm muscle [35].

3. Immunohistochemical study using CD8+ T cells marker to detect their presence in infected muscle tissues using the streptavidinbiotin peroxidase complex method. Immunohistochemistry (IHC) tissue sections were examined by light microscopy (X 400 magnification). Marker expression was recorded by a semi-quantitative grading of brown coloration scheme based upon the percentage of the immune stained area in relation to the total area; low density: $\leq 25 \%$; intermediate density: $>$ $25 \%$ to $\leq 50 \%$; high density: $>50 \%$ of brown coloration [36]. Briefly, according to Rus et al. [37] with modification, after $1 \mathrm{~h}$ incubation of 
muscle section with polyclonal antibody against murine-TNF $\alpha$, at room temperature, were washed for $3 \times 3 \mathrm{~min}$ with PBS/BSA then incubated for $30 \mathrm{~min}$ at room temperature with biotin-rabbit $\mathrm{IgG}$ anti-mouse $\mathrm{IgG}$. Then the sections were incubated for $20 \mathrm{~min}$ with $1 \mathrm{pg} / \mathrm{ml}$ peroxidase-conjugated streptavidin then washed again and were counterstained as described. IHC tissue sections were examined by light microscopy (X 400 magnification). Marker expression was recorded by a semi-quantitative grading of brown coloration scheme based upon the percentage of the immune stained area in relation to the total area.

Statistical analysis: Results were analyzed by the Statistical Package for Social Science (SPSS) for windows version 22.0 with student (t) test and analysis of variance (ANOVA) test to evaluate the possible differences between the study groups. $P$ value $<0.05$ was considered significant.

\section{RESULTS}

\section{A) Parasitological results:}

The results of the effects of CLA, BM MSCs, and the combined injection of them on $T$. spiralis encysted larvae in diaphragms were established in Table (2). Our results showed that the most effective treatment with significant reduction in the number of $T$. spiralis larvae was in group 5 (received CLA + MSCs) followed by group 3 (received CLA only) then group 4 (received MSCs only) with percentage reductions of 85.4 $\%, 82 \%$ and $68.9 \%$, respectively.

So, CLA that showed effective immunization if used alone as in Group 3, was more effective when it was combined with MSCs (Group 5) with significant difference among the results of control and Group 3, 5 ( $P$ value $=0.003$ and 0.002 respectively) and significant difference among the results of control and Group 4 ( $P$ value= $0.011)$. A significant decrease in the mean larval count was detected in all treated groups ( $\mathrm{p}<$ 0.0001 ). The best reduction of larval count was found in Group 5 which received CLA + MSCs followed by Group 3 which received CLA only. The least reduction was detected in Group 4 which received MSCs only. So, on comparing the result, regarding the mean number of larvae of $T$. spiralis showed that CLA + MSCs (Groups 5 ) as a potential combination vaccine caused the highest reduction larvae of $T$. spiralis followed by CLA (Groups 3) then MSCs only (Groups 4). Regarding muscle sections; $T$. spiralis CLA injected group didn't show a statistically significant difference when compared to group immunized with either MSCs or combination $(\mathrm{CLA}+\mathrm{MSCs})(p=0.9$ and 0.89 respectively). Moreover, group immunized with MSCs didn't show a statistically significant difference when compared to group got both MSCs and CLA ( $p=$ 0.8 ). Table 3 demonstrates the statistical correlations in muscle sections of the study groups by Post-hoc Tukey Test.

\section{B) Results of the histopathological studies:}

Sections of mice diaphragm from all groups were stained with special contrast stains, PAS and MT in order to see changes in skeletal muscle bundle, mainly by MT, comment on encysted larvae (viable, degenerated, fibrosed or calcified) and report cellular infiltration with inflammatory cells (plasma cells, lymphocytes), mainly by PAS. In Figure 1 and 2 (A, B, C, D, E), muscle sections in control healthy group (Group 1, A) showed longitudinal section in normal skeletal muscle tissue. While those of infected mice (Group 2, B) showed infection with $T$. spiralis encysted larvae with intact capsule, fibrosis and surrounded by marked chronic inflammatory cell infiltrate. In infected and CLA immunized group (Group 3, C), there were encysted degenerated larvae with intact fibrotic capsule surrounded by moderate chronic inflammatory cell infiltrate. Infected mice immunized with BM MSCs (Group 4, D) showed similar picture to that of Group 3 with numerous encysted degenerated larvae infiltrating the muscle bundles and surrounded by dense chronic inflammatory cell infiltrate (lymphocytes and plasma cells). One cyst showed completely degenerated larvae and replaced by inflammatory cells. The muscle bundles were infiltrated by the inflammatory cells. Infected mice received combined CLA and BM MSCs (Group 5, E) showed degenerated larvae infiltrating the muscle bundles and surrounded by moderate chronic inflammatory cell infiltrate.

\section{C) Results of the immunohistochemical studies:}

In Figure 3 and 4 (A, B, C, D, E) muscle sections from five groups stained by specific stains to study $\mathrm{CD} 8+$ and $\mathrm{TNF} \alpha$ expression, respectively in different groups. G2 (infected only) showed 
absence of CD8+ infiltration. G3 (infected + immunized with CLA) showed moderate density of CD8+ infiltration affecting muscle bundle, G4 (infected + immunized with MSCs) showed high density CD8+ infiltration adherent to the capsule and G5 (infected + immunized with CLA + MSCs) showed high density CD8+ infiltration affecting muscle bundle (Figure 3). However muscle sections from G2 (infected only) showed high density of TNF $\alpha$ infiltration adherent to the capsule and infiltrating muscle bundle; G3 (infected + immunized with CLA) showed moderate density of $\mathrm{TNF} \alpha$ infiltration around some capsule with absence of TNF $\alpha$ infiltration around others. G4 bundle (infected + immunized with MSCs) showed very low density of TNF $\alpha$ infiltration around the capsule and infiltrating muscle and G5 (infected + immunized with CLA + MSCs) showed complete absence of TNF $\alpha$ infiltration around the capsule and muscle bundle (Figure 4).

Table (1): Schedule of immunization and challenge protocol.

\begin{tabular}{|c|c|c|c|c|}
\hline Group & $\begin{array}{c}\text { Immunization with CLA } \\
\text { protocol } \\
\text { (At day } 0 \text { and } 28)\end{array}$ & $\begin{array}{c}\text { Immunization with MSCs } \\
\text { protocol } \\
\text { (At day } 0 \text { and } 28 \text { ) }\end{array}$ & $\begin{array}{l}\text { Challenge } \\
\text { protocol } \\
(\text { At day 56) }\end{array}$ & References \\
\hline Group 1 & - & - & & \\
\hline Group 2 & - & - & $\begin{array}{l}\text { Each mouse } \\
\text { infected orally } \\
\text { with } 500 \mathrm{ML}\end{array}$ & [12] \\
\hline Group 3 & $\begin{array}{c}\text { by iv with } 100 \mu \text { l of vaccine } \\
\text { per mice }\end{array}$ & ( & $\begin{array}{c}\text { Each mouse } \\
\text { infected orally } \\
\text { with } 500 \mathrm{ML} \\
\end{array}$ & [12] \\
\hline Group 4 & - & $\begin{array}{c}1,000,000 \text { cells/mouse was } \\
\text { injected iv }\end{array}$ & $\begin{array}{l}\text { Each mouse } \\
\text { infected orally } \\
\text { with } 500 \mathrm{ML}\end{array}$ & {$[33],[12]$} \\
\hline $\begin{array}{l}\text { Group } \\
5\end{array}$ & $\begin{array}{c}\text { by iv with } 100 \mu \text { l of vaccine } \\
\text { per mice }\end{array}$ & $\begin{array}{l}1,000,000 \text { cells } / \text { mouse was } \\
\text { injected iv }\end{array}$ & $\begin{array}{l}\text { Each mouse } \\
\text { infected orally } \\
\text { with } 500 \mathrm{ML}\end{array}$ & {$[12],[33]$} \\
\hline
\end{tabular}

Table (2): The mean number of $T$. spiralis encysted larvae in mice diaphragms during muscular phase in both control group and tested groups.

\begin{tabular}{|c|c|c|c|}
\hline \multirow{2}{*}{ Groups of the study } & \multicolumn{3}{|c|}{ No. of $T$. spiralis larvae/mice } \\
\hline & $\begin{array}{c}\text { Efficacy } \\
\text { (\% Reduction) }\end{array}$ & Mean \pm SD & Range \\
\hline \begin{tabular}{c} 
Group 1\} $\\
{\text { Healthy Control }}$ & - & $0 \pm 0$ & $0-0$ \\
\hline $\begin{array}{c}\text { Group 21 } \\
\text { Infected Control }\end{array}$ & - & $1715 \pm 985.5$ & $805-3270$ \\
\hline \begin{tabular}{c} 
Group 3\} $\\
{\text { Vaccinated with CLA }}$ & $82 \%$ & $307.2 \pm 127.4$ & $143-480$ \\
\hline \begin{tabular}{c} 
Group 4\} $\\
{\text { Immunized with MSCs }}$ & $68.9 \%$ & $534 \pm 247.9$ & $270-890$ \\
\hline \begin{tabular}{c} 
Group 5\} $\\
{\text { Immunized with (CLA + }} \\
{\text { MSCs) }}$ & $85.4 . \%$ & $251 \pm 113.5$ & $100-405$ \\
\hline $\begin{array}{l}\text { F-T } \\
\text { AN }\end{array}$ & & The & $\begin{array}{l}=10.64 \\
37 * *\end{array}$ \\
\hline
\end{tabular}
\end{tabular}
\end{tabular}
\end{tabular}
\end{tabular}


Table (3): The statistical correlations in muscle sections of the study groups.

\begin{tabular}{|l|l|}
\hline \multicolumn{2}{|c|}{ c } \\
\hline Control infected vs. immunized with CLA & $P$ value $=0.003(\mathrm{~S})^{* *}$ \\
\hline Control infected vs. immunized with MSCs & $P$ value $=0.011(\mathrm{~S})^{*}$ \\
\hline Control infected vs. immunized with CLA +MSCs & $P$ value $=0.002(\mathrm{~S})^{* *}$ \\
\hline Immunized with CLA vs. immunized with MSCs & $P$ value $=0.90(\mathrm{NS})$ \\
\hline Immunized with CLA vs. immunized with CLA + MSCs & $P$ value $=0.89(\mathrm{NS})$ \\
\hline Immunized with MSCs vs. immunized with CLA + MSCs & $P$ value $=0.80(\mathrm{NS})$ \\
\hline
\end{tabular}

S: Significant, NS: Non-significant

$*=P<0.05$

$$
* *=P<0.01
$$
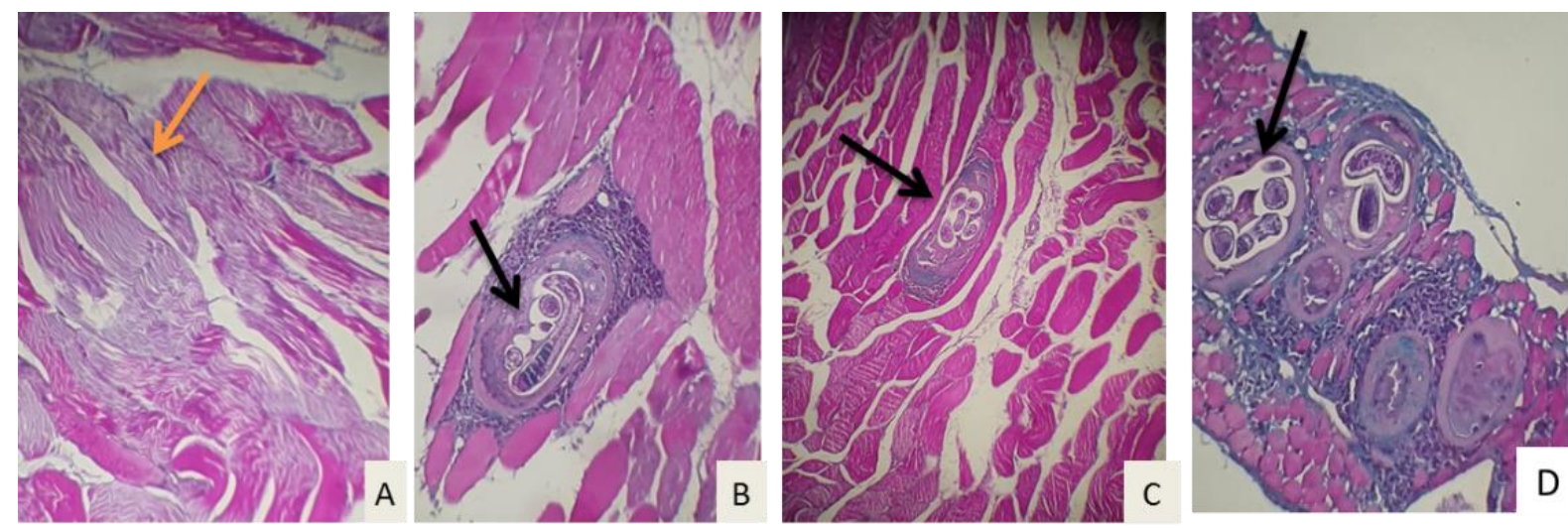

Fig .1 (A,B,C,D,E) A: Photomicrograph of longitudinal section in normal skeletal

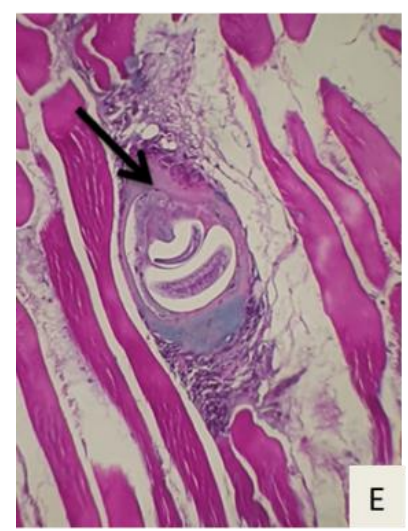
muscles (orange arrow)(Original magnification $\times 200$ ).

B: Photomicrograph of encysted larval (black arrow) with intact capsule showing fibrosis and surrounded by marked chronic inflammatory cell infiltrate (lymphocytes \& plasma cells)(Original magnification x400).

C: Photomicrograph of encysted degenerated larva with intact fibrotic capsule surrounded by moderate chronic inflammatory cell infiltrate (lymphocytes \& plasma cells) (Original magnification $\times 100$ ).

D: Photomicrograph of numerous degenerated encysted larvae surrounded by moderate chronic inflammatory cell infiltrate; one cyst shows completely degenerated larva and replaced by inflammatory cells. The muscle bundles are infiltrated by the inflammatory cells ( Original magnification $\mathrm{x200}$ ).

E: Photomicrograph of completely degenerated encysted larva surrounded by moderate chronic inflammatory cell infiltrate and fibrosis of the capsule(Original magnification $\times 400)(M T)$. 

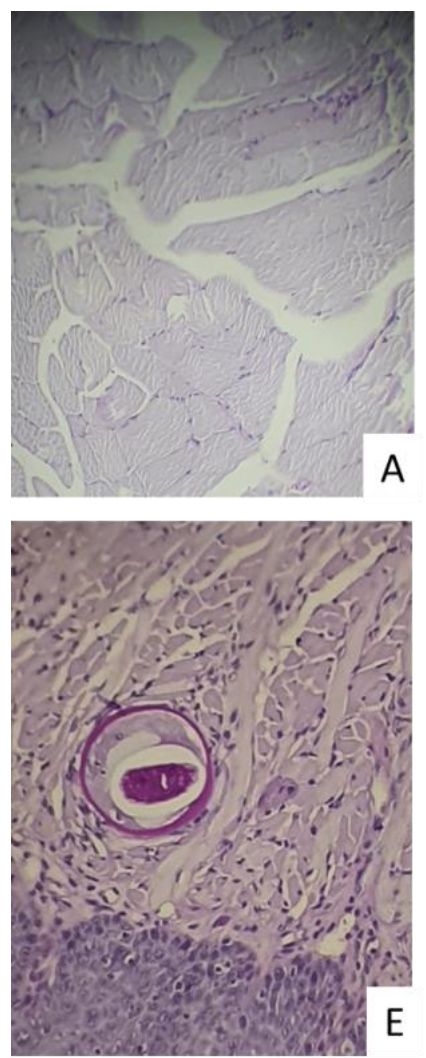
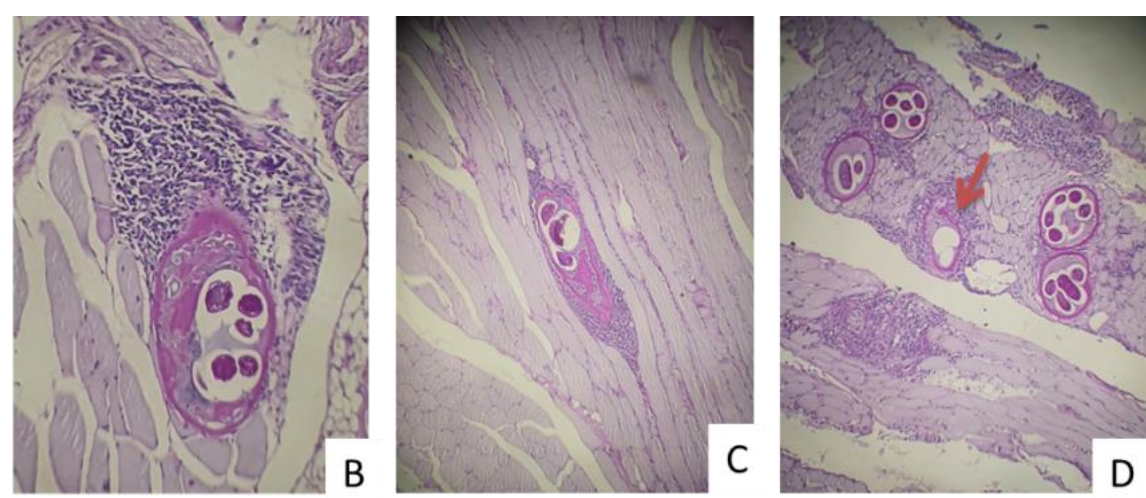

Fig. 2 (A,B,C,D,E) A: Photomicrograph of longitudinal section in normal skeletal muscles (Original magnification $\times 200$ ).

B: Photomicrograph of viable encysted larva with intact capsule surrounded by marked chronic inflammatory cell infiltrate (lymphocytes \& plasma cells)(Original magnification $\mathrm{x} 400)$.

C: Photomicrograph of encysted degenerated larva with intact fibrotic capsule surrounded by moderate chronic inflammatory cell infiltrate (lymphocytes \& plasma cells) (Original magnification $\times 100$ ).

D: Photomicrograph of numerous encysted degenerated larvae infiltrating the muscle bundles and is surrounded by dense chronic inflammatory cell infiltrate. One cyst shows completely degenerated larva (red arrow). The muscle bundles are infiltrated by the inflammatory cells (Original magnification $\times 40$ ).

E: Photomicrograph of encysted degenerated larva infiltrating the muscle bundles and is surrounded by moderate chronic inflammatory cell infiltrate (lymphocytes and plasma cells) (Original magnification $\times 400)(P A S)$.
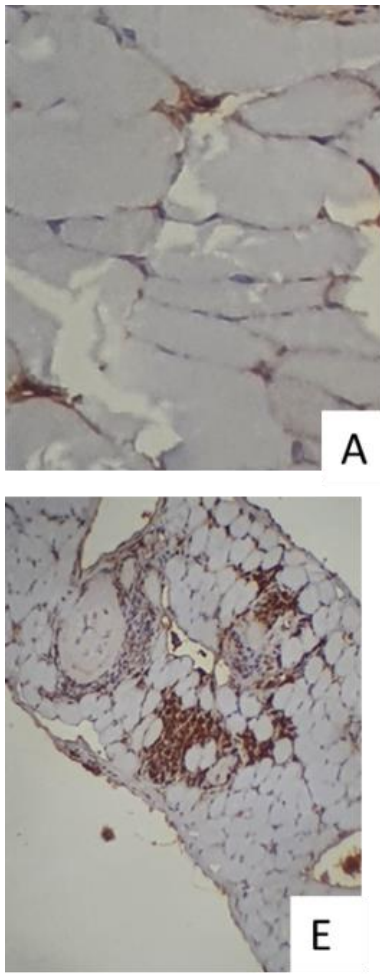
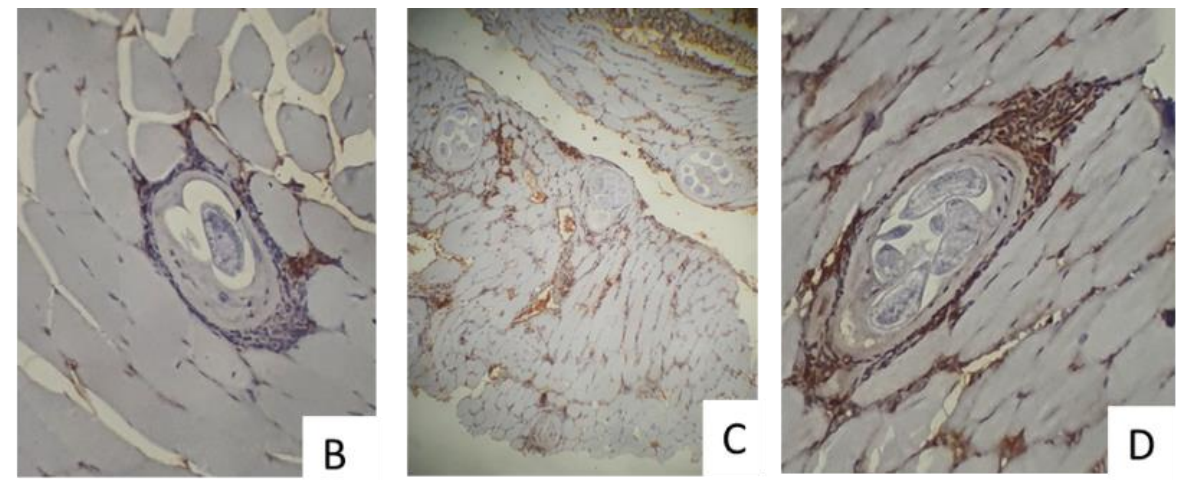

Fig. $3(A, B, C, D, E)$ A: Photomicrograph of cross section in normal skeletal ( Original magnification $\times 200)$.

B: Photomicrograph of absence of infiltrate of $C D 8+$ positive cells surrounding the capsule (Original magnification X200).

C: Photomicrograph of moderate infiltrate of CD8+ positive cells infiltrating the muscle bundles. (Original magnification $\times 100$ ).

D: Photomicrograph of dense infiltrate of CD8+ positive cells surrounding and adherent to the capsule (Original magnification $\mathrm{x} 400$ )

.E: Photomicrograph of dense infiltrate of CD8 +positive cells infiltrating the muscle bundles ( Original magnification $\times 100$ ) IHC, CD8+ 

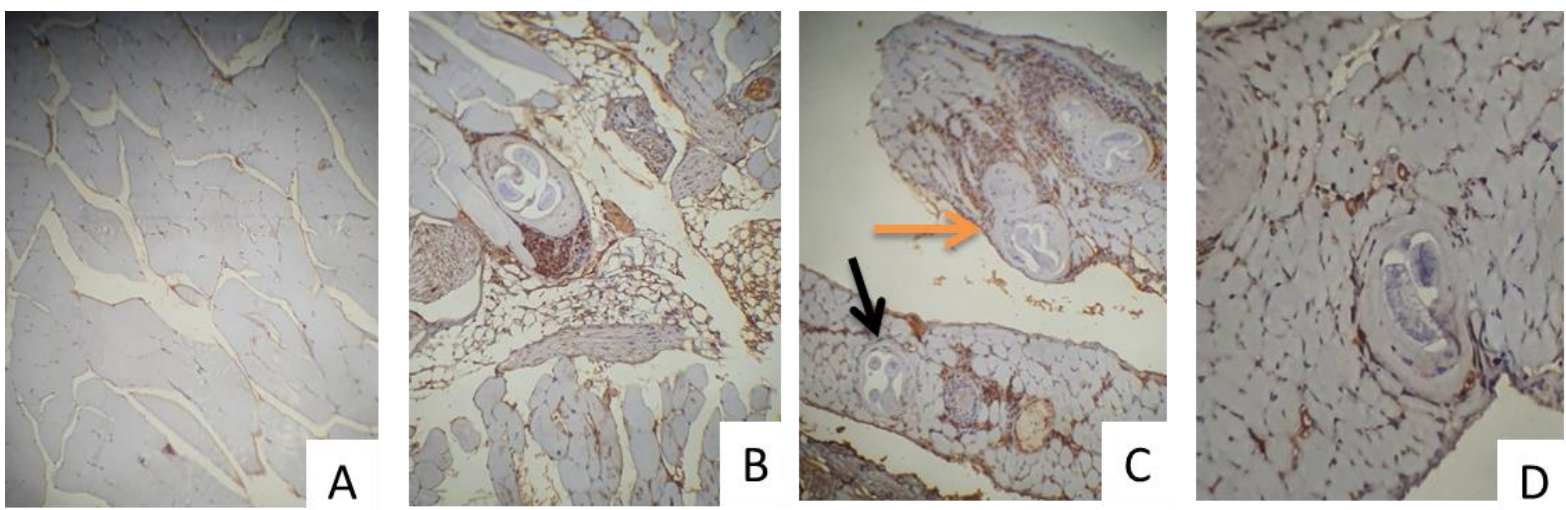

Fig. $4(A, B, C, D, E) A$ : Photomicrograph of longitudinal section in normal skeletal muscle (Original magnification $\times 200$ ).

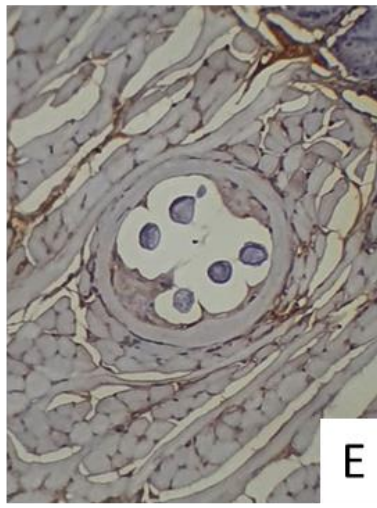

B: Photomicrograph of dense infiltrate of TNF $\alpha$ positive cells adherent to the capsule and infiltrating the muscle bundles (Original magnification $\mathrm{x} 200)$.

C: Photomicrograph of moderate infiltrate of TNFa positive cells surrounding one capsule (orange arrow) with absence of TNF $\alpha$ positive cell around another capsule (black arrow) (Original magnification $\times 100$ ).

D: Photomicrograph of very low TNF $\alpha$ positive cells surrounding encysted larvae and infiltrating the muscle bundles (Original magnification $\times 200$ ).

E: Photomicrograph of complete absence of TNF $\alpha$ positive cells around the

E capsule and infiltrating the muscle bundles (Original magnification $x 400$ ) IHC, TNF $\alpha$

\section{DISCUSSION}

Trichinella spp. is the internationally distributed intestinal nematode worm that produces significant global zoonosis [38]. Improving breeding conditions and controls of the animals entering the food chain is an essential parameter in order to eliminate the disease. Anthelminthic chemical therapy of pigs may also be a way of stopping the disease, still has limitations [39]. So, immunization represents a good option. The nature of the lifecycle, though the large range of antigens are still a challenge to get successful vaccinations [40]. In addition, because raw, pure, recombinant or synthetic antigens are less immunogenic, they may need powerful and effective adjuvants. The selection of the adjuvant must be made in accordance with different parameters to enhance the immune response against the parasite and the defense without causing local or general reactions. Beyond these most essential considerations are the types of immune response, the duration of immunity, the target species, the quality and origin of the antigens and the vaccination route [41].

In the current study, putting in mind that many studies has provided new insights establishing a role for MSCs in other serious parasitic diseases;
MSCs were experimentally tested for schistosomiasis in both immunization[42] and medication[43]. Etewa et al. [42] reported that MSCs as an adjuvant with crude soluble egg antigen (SEA) (a potential anti-schistosomal vaccine) improved their capabilities with a substantial difference compared to FCA with SEA and dramatically reduced the fibrosis dangers of schistosomiasis in murine livers. Moreover, MSCs play a significant role in host defense to malaria by modulating regulatory $\mathrm{T}$ cells [44]. Accordingly, we were encouraged to test BM MSCs as a potential adjuvant for immunization against trichinellosis in murine models. In this study, we used mice to investigate the effect(s) of MSCs alone and combined with CLA on the immune response during parenteral phase of $T$. spiralis infection by histopathological and immunohistochemistry studies analyzing the associated inflammatory/anti-inflammatory mediators besides parasitological study.

The present results showed a significant decrease in the number of $T$. spiralis larvae in muscles of mice treated with CLA, MSCs and combined immunization compared to infected controls. The most effective vaccination with significant

Etewa et al., Afro-Egypt J Infect Endem Dis 2020; 10(3):310-322

https://aeji.journals.ekb.eg/

http://mis.zu.edu.eg/ajied/home.aspx 
reduction in the number of larvae was in group 5 (CLA + MSCs) followed by group 3 (immunized with CLA only) then group 4 (received MSCs only) with percentage reductions of $84.5 \%, 82$ $\%$ and $68.9 \%$, respectively. This result can be explained by the fact that CLA is one of the most effective immunizations against trichinellosis.

Some immunization trials against $T$. spiralis in mice using crude antigen have been successfully performed. Reduction in muscle larvae in vaccinated mice that would result from reduction in female fecundity $[\mathbf{4 5}, \mathbf{4 6}]$. Another successful trial was the use of muscle stage larval antigen with a marked reduction in worm fecundity in hamster [47]. Of those experiments carried out in large animals, a study was conducted in pigs using newborn larvae antigens with FCA that offered development of antibodies with protective effects in animals [48].

In the present study, histopathological results showed that infected mice had numerous encysted larvae with intact capsule showing fibrosis and surrounded by moderate chronic inflammatory cell infiltrate. In infected and CLA immunized mice (Group 3), there were encysted degenerated larvae with intact fibrotic capsules surrounded by moderate chronic inflammatory cell infiltrate. Infected mice immunized with BM MSCs (Group 4) showed similar picture to that of Group 3 with numerous encysted degenerated larvae infiltrating the muscle bundles and surrounded by dense chronic inflammatory cell infiltrate (lymphocytes and plasma cells). Infected mice received combined CLA and BM MSCs (Group 5) showed complete degenerated larvae infiltrating the muscle bundles surrounded by moderate chronic inflammatory cell infiltrate. Our results agreed with Taratuto and Venturiello [49] who stated that muscle biopsy of experimentally affected mice revealed $T$. spiralis larvae coiled within a muscle fiber; host nurse cell enclosed by a capsule. Inflammatory infiltration consists mainly of monocytes, plasma cells, and $\mathrm{T}$ lymphocytes of the suppressor / cytotoxic phenotype. The histology of the host nurse cell varies from that of striated muscle fiber.

Further, another study was conducted on MSCs as a new trend in treatment of $T$. spiralis in experimentally infected mice; histological presentation of mice diaphragm of MSCs treated category showed encysted larvae surrounded by thick intact capsule and slight inflammatory and granulated cell infiltrate, with few cells adhering to the larvae. While mice group got combined treatment; MSCs and Mebendazole, the larvae were collapsed with damaged capsules that have been infiltrated by inflammatory cells. Many helminthes parasitic infections redirect immune to Th2 and T regulatory responses and murine results suggest that immune suppressions caused by cross-mucosal inhibition of regulating cytokines, CD4+ and CD8+ regulatory T-cells (Tregs) [50]. Human CD8+ Tregs have been examined so much less than CD4 + Tregs. Even though they were among the "suppressor cells" that were first recognized. Besides, CD8+ Tregs are generally re-emerging as important players, including human infectious, parasitic diseases and vaccination afterwards [51]. Th2 responses, characterized by development of interleukin (IL)-4, IL-5 and IL-13, have been shown to be essential in the prevention of helminthic infections and producing medical problems including atopy and asthma [52].

It is well established that Th1 and Th2 cells released cytokines behave antagonistically and control each other mutually; however, the factors responsible for regulating Th1 and Th2 cytokines during immune response remain unknown [53]. One of the impacts of TNF $\alpha$ is the production of inducible nitric oxide synthase, leading to the production of nitric oxide (NO), which acts primarily as an effector molecule against both extracellular and intracellular parasites. However, several researches have shown that the $\mathrm{TNF} \alpha$ and NO-driven inflammatory response is harmful to the host, as they promote enteropathy development [54].

Immunohistochemical studies showed that muscle sections from G2 (infected only) showed absence of CD8+ infiltration. G3 (infected + immunized with CLA) showed moderate density of CD8+ infiltration affecting muscle bundle, G4 (infected + immunized with MSCs) showed high density CD8+ infiltration adherent to the capsule and G5 (infected + immunized with CLA + MSCs) showed high density CD8+ infiltration affecting muscle bundle. In support of our results, Quan et al. [55] claimed that the production of spleen and blood CD4+, CD8+ and the $\mathrm{CD} 4+/ \mathrm{CD} 8+$ ratio increased dramatically compared with the control. Such results support immunization with $T$. spiralis muscle stage larva ES-antigens may develop a powerful immune response and provide full protection against infected larvae. Furthermore, another study 
displayed that the amounts of splenic CD4+ and CD8+ T cell of $T$. spiralis as well as T. britovi in both the intestinal process and the muscle process of contaminated mice, increased dramatically. Decreased numbers of CD4+ and $\mathrm{CD} 8+\mathrm{T}$ cells post $T$. pseudospiralis infection indicate cellular immunity reduction. Both the encapsulating species of Trichinella mediated the Th2 response during the intestinal phase and the advanced muscle phase [56]. In the other side, the proportion of $\mathrm{CD} 8+$ cells of the vaccinated mice with CLA and ES components generated from first stage $T$. spiralis larvae (L1) enclosed in microcapsules, did not display any difference compared to the controls [30].

In our study, we reported that muscle sections from G2 (infected only) showed high density of $\mathrm{TNF} \alpha$ infiltration adherent to the capsule and infiltrating muscle bundle; G3 (infected + immunized with CLA) showed moderate density of TNF $\alpha$ infiltration around some capsule with absence of TNF $\alpha$ infiltration around others. G4 (infected + immunized with MSCs) showed very low density of TNF $\alpha$ infiltration around the capsule and infiltrating muscle bundle and G5 (infected + immunized with CLA + MSCs) showed complete absence of TNF $\alpha$ infiltration around the capsule and muscle bundle. Interestingly, our results regarding to $\mathrm{TNF} \alpha$ were consistent with the results of previous studies reporting that a significant major element of ES antigen of $T$. spiralis, recombinant $T$. spiralis $53-\mathrm{kDa}$ protein had a beneficial effects in substantially down-regulated TNF $\alpha$, and vice versa up-regulated Th2 cytokines (IL-4, IL-13) in the sera of a colitis-induced mice model [57]. Also, Guo et al. [58] found that T. spiralis paramyosin (Pmy) triggered dendritic cells derived from the mouse BM and stimulated regulatory $\mathrm{T}$ cells which have secreted high TNF $\alpha$ levels. Regarding T. spiralis infection, Pmy plays a significant function in the regulation of the host immune system. At the other hand, this cytokine is essential in the initial inflammatory reaction found in Trichinellainfected hosts.

Activation of mast cells by $T$. spiralis larvae-1 antigens induced cytokine mRNA expression and release of TNF $\alpha$ [59]. The rate of $\mathrm{TNF} \alpha$ had dramatically raised from days 4 pi as well as weeks 9 pi. This means that it increases in both enteric and muscular phase of infection. The stimulation of macrophages during $T$. spiralis infection may result not only in the development of TNF $\alpha$ but also to the production of interferon gamma (IFN- $\gamma$ ). Moreover, IFN- $\gamma$ produced by T cells triggers macrophages to secrete TNF $\alpha$. In addition, $\mathrm{TNF} \alpha$, in combination with IFN- $\gamma$, stimulates murine macrophages and generates reactive oxygen species that progressively kill parasites through a process of lipid peroxidation [53]. These observations quite correlate with our study. This is in agreement with Etewa et al. [60] who reported that $\mathrm{TNF} \alpha$ was at high level on the $7^{\text {th }}$ and $40^{\text {th }}$ days in the control infected group as it increased as proinflammatory cytokines, while significant decrease of $\mathrm{TNF} \alpha$ in thiabendazole-tested group compared to other groups. In relation to thiabendazole-tested group, it showed the lowest level of TNF $\alpha$ on both phases, mostly due to its protective effect against T. spiralis.

\section{CONCLUSION}

We concluded that immunization with CLA combined BM MSCs as an adjuvant generates the Th2-mediated responses with increased $\mathrm{CD} 8+$ cell infiltration and decreased TNF- $\alpha$ required for immunity against trichinosis with 85.4.\% reduction in muscle larva compared with the control group. The analysis of this unique model of helminthic infection is likely to make a significant contribution to understanding the fine processes underlying the host-helminth interactions. This will be of great importance not only in the preparation of reliable vaccines but also in the advancement of knowledge in the areas of immunology and parasitology. CLABM MSCs combination offers a practical and successful approach to manage trichinellosis in both human and domestic animals. More studies are needed with different routes of administration of BM MSCs with different preparations of $T$. spiralis vaccine.

Conflict of interest: There is no conflict of interest.

\section{Financial support and sponsorship: Nil.}

Ethical consideration: All mice were reared and sacrificed according to the international guidelines approved by The Institutional Animal Care and Use Committee, Zagazig University (IACUC-ZU). 


\section{REFERENCES}

1. Gottstein B, Pozio E, Nockler K, Epidemiology, Diagnosis, Treatment, and Control of Trichinellosis. Clin Microbiol Rev. 2009; 22(1):127-145.

2. Helmby $\mathrm{H}$, Grencis RK. IL-18 regulates intestinal mastocytosis and Th2 cytokine production independently of IFN-gamma during Trichinella spiralis infection. J Immunol. 2002; 169:25532560.

3. Dupouy-Camet J. Trichinellosis: a worldwide zoonosis. Vet Parasitol. 2000; 93(3-4):191-200.

4. Marian I, Ionică AM, Deak G, Ursache T, Lefkaditis M, Gherman CM, et al. The effect of Trichinella spiralis on muscular activity of experimentally infected mice. Parasitol Int. 2020; 1(76): 102032.

5. Kociecka W. Trichinellosis: human disease, diagnosis and treatment. Vet Parasitol. 2000; 93:365-83.

6. Garc1'a A, Barrera MG, Piccirilli G, Vasconi MD, Di Masso RJ, Leonardi D, et al. Novel albendazole formulations given during the intestinal phase of Trichinella spiralis infection reduce effectively parasitic muscle burden in mice. Parasitol Int. 2013; 62:568-570.

7. Zhang $\mathrm{N}, \mathrm{Li} \mathrm{W}, \mathrm{Fu}$ B. Vaccines against Trichinella spiralis: progress, challenges and future prospects. Transbound Emerg Dis. 2018; 65(6):1447-58.

8. Wang ZQ, Liu RD, Sun GG, Song, YY, Jiang P, Zhang X, et al. Proteomic analysis of Trichinella spiralis adult worm excretory-secretory proteins recognized by sera of patients with early trichinellosis. Front Microbiol. 2017; 8, 986.

9. Cui J, Wang L, Sun GG, Liu LN, Zhang SB, Liu $\mathrm{RD}$, et al. Characterization of a Trichinella spiralis $31 \mathrm{kDa}$ protein and its potential application for the serodiagnosis of trichinellosis. Acta Tropica. 2015; 142: 57-63.

10. Pozio E, Sacchini D, Sacchi L, Tamburrini A, Alberici F. Failure of mebendazole in the treatment of humans with Trichinella spiralis infection at the stage of encapsulating larvae. Clin Infect Dis. 2001; 32: 638-642.

11. Wang L, Wang X, Bi K, Sun X, Yang J, Gu Y, et al. Oral Vaccination with Attenuated Salmonella typhimurium-Delivered TsPmy DNA Vaccine Elicits Protective Immunity against Trichinella spiralis in BALB/c Mice. PLoS Negl Trop Dis. 2016; 10(9): e0004952.

12. Deville S, de Pooter A, Aucouturier J, Lainé-Prade V, Cote M, Boireau P, et al. Influence of adjuvant formulation on the induced protection of mice immunized with total soluble antigen of Trichinella spiralis. Vet Parasitol. 2005; 5, 132(12):75-80.

13. Lightowlers MW, Rickard MD. Excretorysecretory products of helminth parasites: Effects on host immune responses. Parasitol. 1998; 96, S123-S166.

14. Gruden-Movsesijan A, Ilic N, SofronicMilosavljevic L. 2002. Lectinblot analyses of Trichinella spiralis muscle larvae excretorysecretory components. Parasitol Res. 2002; 88: 1004-1007.

15. Vogel FR. Improving vaccine performance with adjuvants. Clin Infect Dis. 2000; 30: S266- 70.

16. Yang J, Gu Y, Yang Y, Wei J, Wang S, Cui S, et al. Trichinella spiralis: immune response and protective immunity elicited by recombinant paramyosin formulated with different adjuvants. Exp Parasitol. 2010; 1,124(4):403-8.

17. Hacariz O, Sayers G, McCullough M, Garrett M, O'Donovan J, Mulcahy G. The effect of Quil A adjuvant on the course of experimental Fasciola hepatica infection in sheep. Vaccine. 2009; 27:4550.

18. Wang W, Singh M. Selection of adjuvants for enhanced vaccine potency. World J Vaccines. 2011; 1:33-78.

19. Saad MA, Hasby EA. Trichinella Spiralis Impact on Mesenchymal Stem Cells: Immunohistochemical Study by Image Analyzer in Murine Model. Exp Mol Pathol. 2017; 102(3): 396-407.

20. Svobodova E, Krulova M, Zajicova A, Pokorna K, Prochazkova J, Trosan $\mathrm{P}$, et al. The role of mouse mesenchymal stem cells in differentiation of naive $\mathrm{T}$-cells into anti-inflammatory regulatory T-cell or proinflammatory helper T-cell 17 population. Stem Cells Dev. 2012; 21 (6): 901-910.

21. Conget P, Minguell JJ. Phenotypical and functional properties of human bone marrow mesenchymal progenitor cells. J Cell Physiol. 1999; 181: 67-73.

22. Malgieri A, Kantzari E, Patrizi M P, Gambardella S. Bone marrow and umbilical cord blood human mesenchymal stem cells: state of the art. Int J Clin Exp Med. 2010; 3 (4): 248-269.

23. Najar M, Raicevic G, Fayyad-Kazan H, Bron D, Toungouz M, Lagneaux L. Mesenchymal stromal cells and immunomodulation: a gathering of regulatory immune cells. Cytotherapy. 2016; 18 (2): 160-171.

24. Dennis JE, Merriam A, Awadallah A, Yoo JU, Johnstone B, Caplan AI. A quadripotential mesenchymal progenitor cell isolated from the marrow of an adult mouse. J Bone Miner Res. 1999; 14(5):700-9.

25. Shokir RA. Studies on mesenchymal stem cells as a new trend in treatment of Trichinella spiralis in experimentally infected mice. M.Sc. Thesis, Faculty of Science, Zagazig University, Egypt. 2019: 102-108.

26. Freyman T, Polin G, Osman H. A quantitative, randomized study evaluating three methods of mesenchymal stem cell delivery following 
myocardial infarction. Eur Heart J. 2006; 27: 1114-1122.

27. Dimmeler S, Burchfield J, Zeiher AM. Cell-based therapy of myocardial infarction. Arterioscler Thromb Vasc Biol. 2008; 1, 28(2):208-16.

28. Fischer UM, Harting MT, Jimenez F, MonzonPosadas WO, Xue H, Savitz SI, et al. Pulmonary passage is a major obstacle for intravenous stem cell delivery: the pulmonary first-pass effect. Stem Cells Dev. 2009; 18(5):683-92.

29. Kohn DF, Wixson SK, White WJ, Benson GJ. Anesthesia and analgesia in laboratory animals. Elsevier; New York: Academic Press. 1997:165205.

30. Dea-Ayuela MA, Rama-Iñiguez S, BolasFernández F. Vaccination of mice against intestinal Trichinella spiralis infections by oral administration of antigens microencapsulated in methacrilic acid copolymers. Vaccine. 2006; 5, 24(15):2772-80.

31. Bradford MM. A rapid and sensitive method for the quantitation of microgram quantities of protein utilizing the principle of protein-dye binding. Anal Biochem. 1976; 72:248-54.

32. Etewa SE, Al-Hoot AA, Abdelmoaty SM, Mohammad SM, Moawad HS, Sarhan MH, et al. The Outcomes of Mesenchymal Stem Cells Therapy for Experimental Toxoplasmosis. PUJ. 2019; 1, 12(1):34-44.

33. Cho KA, Ju SY, Cho SJ, Jung YJ, Woo SY, Seoh JY, et al. Mesenchymal stem cells showed the highest potential for the regeneration of injured liver tissue compared with other subpopulations of the bone marrow. Cell Biol Int. 2009; 33(7): 772777.

34. Guenther S, No“ckler K, von Nickisch-Rosenegk M, Landgraf M, Ewers C, Wieler LH, et al. Detection of $T$. spiralis, T. britovi and $T$. pseudospiralis in muscle tissue with real-time PCR. J Micro-Boil Methods. 2008; 75:287-292.

35. Bancroft JD, Gamble M. Theory and practice of histological techniques $\left(7^{\text {th }}\right.$ ed.). Churchill Livingstone/Elsevier; China. 2013: 83 -90.

36. Cote SL, Riberio-Da-Silva A, Cuello AC. Current protocols for light microscopy immunehistochemistry. In: Cuello AC (Ed.) Immunohistochemistry II. Chichester: John Wiley \& Sons. 1994: 148-167.

37. Rus FG, Niculescu F, Vlaicu R. Tumor necrosis factor-alpha in human arterial wall with atherosclerosis. Atherosclerosis. 1991; 1, 89(2):247-54.

38. Miterpáková M, Hurníková Z, Antolová D, Dubinský P. Endoparasites of red fox (Vulpes vulpes) in the Slovak Republic with the emphasis on zoonotic species Echinococcus multilocularis and Trichinella spp. Helminthologia. 2009; 46:7379.

39. Aucouturier J, Deville S, Perret C, Vallée I, Boireau P. Assessment of efficacy and safety of various adjuvant formulations with a total soluble extract of Trichinella spiralis. Parasite. 2001a; 1, 8: S126-32.

40. Gu Y, Li J, Zhu X, Yang J, Li Q, Liu Z, et al. Trichinella spiralis: characterization of phagedisplayed specific epitopes and their protective immunity in BALB/c mice. Exp parasitol. 2008; 1, 118(1):66-74.

41. Aucouturier J, Dupuis L, Ganne V. Adjuvants designed for veterinary and human vaccines. Vaccine. 2001b; 21, 19(17-19):2666-72.

42. Etewa SE, Abd Allah SH, Badawey MSR, Shalaby SM, El-Shal AS, El Shafey MA, et al. The effect of stem cells as an adjuvant on the immunogenicity of a potential anti-schistosomal vaccine in mice. J Egypt Soc Parasitol. 2016; 46(3): 693-716.

43. Abou Rayia DM, Elmarhoumy SM, Ismail HH, Elchennawy FA, Zalata KR. The outcomes of bone marrow stromal cell therapy in schistosomal hepatic fibrosis: an experimental study. J Egypt Soc Parasitol. 2017; 47(3):633-6.

44. Thakur RS, Tousif S, Awasthi V, Sanyal A, Atul PK, Punia $\mathrm{P}$, et al. Mesenchymal stem cells play an important role in host protective immune responses against malaria by modulating regulatory $\mathrm{T}$ cells. Eur J Immunol. 2013; 43(8):2070-7.

45. Sun S, Xu W, He N, Sugane K. An antigenic recombinant fusion protein from Trichinella spiralis induces a protective response in Balb/mice. J Helminthol. 1994; 68, 89-91.

46. Darwish RA, Sanad MM, Youssef SM. Immunization against Trichinella spiralis using antigens from different life-cycle stages experimental study in mice. J Egypt Soc Parasitol. 1996; 26(1): 19-26.

47. Behnke JM, Dehlawi MS, Rose R, Spyropoulos PN. The response of hamsters to primary and secondary infection with Trichinella spiralis and to vaccination with. J Helminthol. 1994; 68:28794.

48. Marti HP, Murrell KD, Gamble HR. Trichinella spiralis: immunization of pigs with newborn larval antigens. Exp parasitol. 1987; 1, 63(1):68-73.

49. Taratuto AL, Venturiello SM. Trichinosis. Brain pathol. 1997; 7(1):663-72.

50. Weinstock JV, Elliott DE. Helminth infections decrease host susceptibility to immune-mediated diseases. J Immunol. 2014; 1,193(7):3239-47.

51. Boer MC, Joosten SA, Ottenhoff TH. Regulatory T-cells at the interface between human host and pathogens in infectious diseases and vaccination. Front Immunol. 2015; 11; 6: 217.

52. Scales HE, Ierna MX, Lawrence CE. The role of IL-4, IL-13 and IL-4R $\alpha$ in the development of protective and pathological responses to Trichinella spiralis. Parasit Immunol. 2007; 29(2):81-91. 
53. Farid AS, Fath EM, Mido S, Nonaka N, Horii Y. Hepatoprotective immune response during Trichinella spiralis infection in mice. $J$ Vet Med Sci. 2019; 81(2):169-176.

54. Muñoz-Carrillo JL, Muñoz-Escobedo JJ, Maldonado-Tapia $\mathrm{CH}$, Chávez-Ruvalcaba $\mathrm{F}$, Moreno-García MA. Resiniferatoxin lowers TNF- $\alpha$, NO and PGE2 in the intestinal phase and the parasite burden in the muscular phase of Trichinella spiralis infection. Parasit Immunol. 2017; 39(1):e12393.

55. Quan FS, Matsumoto T, Lee JB, Timothy O, Lee JS, Kim TS, et al. Immunization with Trichinella spiralis Korean isolate larval excretory-secretory antigen induces protection and lymphocyte subset changes in rats- Immunol Invest. 2004; 1, 33(1):15-26.

56. Dvorožňáková E， Hurníková Z, KołodziejSobocińska M. Development of cellular immune response of mice to infection with low doses of Trichinella spiralis, Trichinella britovi and
Trichinella pseudospiralis larvae. Parasitol Res. 2011;1,108(1):169-76

57. Du L, Tang H, Ma Z, Xu J, Gao W, Chen J, et al. The protective effect of the recombinant $53-\mathrm{kDa}$ protein of Trichinella spiralis on experimental colitis in mice. Dig Dis Sci. 2011; 56(10):2810-7.

58. Guo K, Sun X, Gu Y, Wang Z, Huang J, Zhu X. Trichinella spiralis paramyosin activates mouse bone marrow-derived dendritic cells and induces regulatory T cells. Parasit Vectors. 2016 ;9(1):1-1

59. Niborski V, Vallée I, Fonseca-Liñán R, Boireau P, Enciso A, Ortega-Pierres $\mathrm{G}$, et al. Trichinella spiralis: Stimulation of mast cells by TSL-1 antigens trigger cytokine mRNA expression and release of IL-4 and TNF through an Igindependent pathway. Exp Parasitol. 2004; 1;108(3-4):101-8.

60. Etewa SE, Fathy GM, Abdel-Rahman SA, Abd ElKhalik D, Sarhan MH, Badawey MS. The impact of anthelminthic therapeutics on serological and tissues apoptotic changes induced by experimental trichinosis. J Parasit Dis. 2018; 1, 42(2):232-42. 